\title{
E-commerce in Healthcare: A Case Study on Promoting the Therapeutic Hardware
}

\author{
Azza Abdel Monem ${ }^{1, a}$ \\ ${ }^{1}$ Faculty of Computer \& Information Sciences, Ain Shams University, Abbassia, 11566, Cairo, Egypt
}

\begin{abstract}
The E-commerce and Internet permit enormous organizations to act like little ones and little organizations to act huge. The test to organizations is to make exchanges in the form of transactions less expensive and simpler for themselves as well as less demanding and more advantageous for clients and suppliers. This paper introduces a proposition for the foundation of a business that will encourage the offer of restorative hardware to social insurance organizations in the United Arab Emirates UAE. This case concentrates on the offer of different therapeutic hardware including wheelchairs, restorative programming, medicinal equipment's, in vitro calibrators as additional medicinal gadgets. The medicinal gadgets can be loaded by the business will consolidate items from various producers to provide food to serve the fluctuating purchaser taste and inclinations. The business who desires to require the backing of financial specialists in the business which is through Internet, so as to subsidize the foundation of a remarkable unique endeavour for the individuals working in for a business.
\end{abstract}

Key Words. E-commerce, E-Business, Management Information Systems, Healthcare, Medical Devices, Information System.

\section{Introduction}

The online world is another set of repeated exercise that consolidates the use of Web 2.0 to encourage deals in the form of sale. The fresh pattern is alluded to as Sales 2.0 that has expanded the ability to sell online. Besides, Web 2.0 dispense a rough and ready stage that is proper for putting sales into operation online. Web 2.0 offers a development that fuses the dynamic increment in the refinement of innovation because of the immense selection of the web, in this manner the influence is evident on the association of individuals in the present world. Essential mainstays of Web 2.0 is joint effort along these lines allowing individuals from everywhere throughout the world to cooperate and open out information in a way that was beforehand inconceivable [5]. This has permitted individuals to share their mental impressions, trusts, considerations and dreams subsequently rendering them open to different gatherings on the web.

The business will go for tackling the ability to do something given by Web 2.0 and to put these capabilities to build the promotion and sales strengths of the business. The online community proposition will help in the expansion of comprehension and association with various

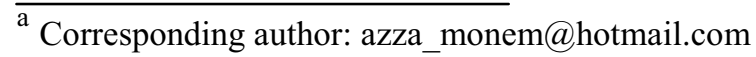

customers and subsequently expand the business sector for the offer of medicinal hardware online [8].

The web has brought about a considerable revamp in the costs of products, the information and presentation that is given to the clients and gave a fitting estimation of the reaction of various shoppers to the modifications in the business sector inclinations. It is imperative to note that there is an amendment in personalizing publicize information in the form of advertisements of products, the retail rehearse and the adaptability of sales to clear the learning path. The utilization of online stages is noteworthy to encourage the exploration of the business sector patterns via the investigation of the sales and purchaser inclinations from the hunt devices gave on the Internet stage [13]. This has brought about a variety in the costing schemes utilized as a part of online sales.

Information systems will undoubtedly enhance the execution of the business through helping with the advancement of new items and venture into upcoming markets for the business. The expansion in openness of the business sector will undoubtedly enhance the execution of the business [22]. It is fundamental to make a note that an Internet store does not exist in the United Arab Emirates that practices the sale of therapeutic (medicinal) hardware. In this way, the business will 
undoubtedly pick up prominence from the sale of restorative hardware on the web.

Information Systems have likewise demonstrated influential in the data capacity as well the data examination in detail that might be placed in the storage. Accordingly, the information systems will be utilize by the business and stockpiling of accounts in the repository as well business data examination will take place, keeping in mind the end goal is to encourage the fulfilment of precise results.

Online networking sites permit people to speak with each other keeping in mind the end goal to create individual connections. At the point when organizations interface these social sites, purchasers are capable partner with them specifically. That association can be near customers than standard methodologies connected in outbound promoting and showcasing. In this manner the business will apply online networking sites in showcasing the business to build the customers [13].

Online networking correlation destinations develop as verbal relationship with various people both universally and provincially. Individual to individual correspondence and web diaries allow the members to "tweet again and again" or "post again and again" on the comments made by people online, for this situation, the comments that are made in line to the business [6]. Through reiterating the message, the customer's affiliations can watch the message, then getting viral to many other peoples. More movement is passed on the entity or firm based on the information that is shown there about that entity. Through individual to individual correspondence ends points, association's connection with people can take place who are keen on the items sold by the organization. This joint effort which is individual based can build a divergence of trust of supporters and potential customers in the business exercises. In like manner, by picking whom to take after on these destinations, items can accomplish surprisingly expansive target gathering of people.

Long range casual correspondence, similarly, fuse an unfathomable data measure about what items and organizations arranged clients might be keen on. Through the usage of new Semantic Analysis progressions, promoters can perceive obtaining inclinations, for instance, substance ration out by people and request posted on the web. Cognizance of obtaining signs can offer the business some assistance with targeting correlated prospects and publicists run scaled down scale concentrated on promoting effort.

The business will likewise utilize comparative sites and healing (hospitality) facility sites to build the compass of the business to individuals having comparative intrigues accordingly might frame potential customers for the business. It is necessary that the promoting effort incorporate the business contact data to guarantee that individuals can call the business if there should be an occurrence of any request.

The strategy for success displayed goes for giving an online stage to encourage the selling of medical gadgets on the web. Therapeutic (Medical) gadgets fuse a scope of contraption and instruments that are utilized to encourage treatment for patients confronting distinctive infirmities. Along these lines, medical gadgets incorporate every one of the instruments mechanical assembly, in vitro gear and embeds that are connected in the treatment, conclusion and examination of various restorative conditions [9]. It is essential to note that medical gadgets don't bring about any concoction activity when connected in therapeutic (medical) applications; therefore, they can't be named drugs [15].

Keeping in mind the end goal to comprehend the business, the most indispensable thing is to acknowledge the meaning of a therapeutic (Medical) gadgets as exhibited by WHO (World Health Organization):

Medical gadget is any instrument, hardware, apparatus, machine, insert, programming, or other connected, proposed by the maker for the accompanying points:

- Conclusion, evasion, recognition, treatment or administration of ailment or harm

- Analysis, replacement, regulation, or bolster anatomical or physiological exercises.

- supporting or look after life

- Disinfection of hardware with respect to healthcare [16].

The paper is sorted out as takes after: the following segment introduces the writing audit concentrating on the qualities of e-commerce and the hypothetical establishments, trailed by the contextual investigation model depiction. The ensuing sections depict the targeted objective, model procedure, aftereffects of the contextual investigation model and conclusions, including the clients' study about applying this model.

\section{Background}

While examining, we receive a wide meanings of ecommerce to incorporate the exchanges and relevant intelligent business forms which might have happened previously, then after the fact those exchanges, using Internet, handheld cell phones and remote correspondence systems to lead the exchanges [18]. This segment will talk about the e-commerce methodologies, Business to Business (B2B) human services e-commerce and the advantages of e-wellbeing. 


\subsection{Strategies of E-commerce}

The desires of customers when it comes to quality healthcare are high due to the quick headway in technology [14]. Doctor's facilities, clinical centres and other health care suppliers need to meet the customer desire whilst doing it in the most cost-productive way. In [6] clarified the huge effect e-commerce might impact cost, proficiency, as well distinction of the general type of administration and conveyance of health care administrations. Effectiveness picks up inside of the health care world which is credible to the use of IT (Information Technology) and, most particularly, the Internet. [6] The proper e-commerce plans of action redid and grew in like manner, it would achieve the objective of productive healthcare administration at lower expenses. In [6] discuss the advantages e-commerce (also called e-health) effect health care. E-commerce procedures usage will bolster healthcare suppliers work all the more productively particularly the ones utilizing back-dated systems which are paper-based [14]. The advantages are that clinics and specialists can see a patient's complete medicinal record of previous history and give the right finding. This spares the patient a lot of time. 'Briggs and Early3 talked about how Internet technology improvements had influenced the way healthcare is given.' In [3] characterizes the electronic health record (EHR) as "an electronic longitudinal accumulation pertaining to an individual wellbeing information generally taking into account the individual, entered or acknowledged by medicinal services suppliers, which can be circulated over various locales or collected at a specific source". EHR, a component that incorporates victim information into the up and coming era of health information advances with respect to the new technologies, containing Computerized Physician Order Entry (CPOE) and Clinical Decision Support Systems (CDSS), and by and large enhance the nature of purpose of-consideration choice making [14].

With the utilization of appropriate IT framework and information frameworks (systems), conventional paperbased frameworks will be minimized or dispensed with later on. [23] recorded the IT-drove framework change is fixated on different crossing advances(technologies) that might be gathered as tracking(following up), entry, choice backing and reporting:

- "Following or Tracking" or distinguishing advancements (technologies), for example, standardized tags and going with scanners emphatically recognize medications, measurements and patients(sufferers) [14]. (RFID) Radio Frequency Identification illustrated as "track and follow" advances might swap standardized tag technologies for recognizing assignments and permit further tracking of medications and, possibly, patients.

- "Passage" advancements are spoken to by automated doctor request section termed as (CPOE) systems, here CPOE stands for computerized physician order entry, that maintain a strategic distance from drug blunders brought on by crabbed and additional recording botches [17].

- "Choice bolster innovations or decision support technologies" (CDSS) are developed request section systems that have vanished their inactivity and related drug communication info, data from EHR, or treatment models, (for example, clinical practice rules), and which offer sensible favourable circumstances over basic $\mathrm{CPOE}$ systems [14]. Relevant are intelligent gadgets, for example, apparatuses utilized for tele-care that gather and keep track of information from remote patients and trigger future assessment and solve the health issue through appropriate treatment.

- "Reporting" systems accommodate unfavourable occasion and medicinal blunder divulgence and reporting and encourage results research. [23] Illustrated in writing about the development rate in Internet access and every one of the enhancements in execution coming about because of fresh technologies, specifically in the ranges of telemedicine and in correspondence in the middle of patient and healthcare experts. Advanced IT influences the conveyance of healthcare, as well as can essentially impact the specialist (doctor) - tolerant (patient) relationship [17].

\subsection{Business 2 Business Healthcare \& Supply Chain Management Systems}

As e-commerce incomplete existence exploited/boosted to its maximum capacity because of individuals not having the capacity to completely let go of custom and grasp fresh technologies [14]. The way to the achievement lies generally in the full cooperation of purchasers and medicinal services suppliers. Medicinal services: B2B. B2B health care e-commerce incorporates exchanges and the trading of information among sellers, healing facilities, protection organizations, state and government controllers, and specialists' workplaces where patients - the end buyers - are not straightforwardly included. A decent approach to begin is for hospitals, clinical centres, drug stores and other medicinal services establishments to consolidate ecommerce and (SCM) Supply Chain Management. From the point of view of Operations Management, [10] expressed the centre in the medicinal services part focused on advancing individual procedures.

Examples are the utilization of operations exploration systems to improve stock levels of medications and strategies for upgrading the requesting procedure of safe keeping related items and pharmaceuticals. In [18] clarified that these days information and correspondence (communication) advances can assume a critical part in enhancing supply chains in health and it will be of nothing unexpected that numerous medicinal services associations have begun up ventures in the field of health supply chains. With the watchful usage of SCM, costs 
will decay. A SCM framework would deal with the medicinal services supplier's association with suppliers particularly since most choice making spin around the overseeing of therapeutic (medicinal) items and supplies. They can share data about requests, creation, stock levels, conveyance of items and administrations. The objective is to convey the perfect measure of item to the destination with minimal measure of time and most reduced expense. Therefore, a stock renewal framework could be actualized where the framework (system) keeps a day by day record of stock-levels and naturally arranges for new or future stock, sent and conveyed when required.

[14] The utilization of Skype and online video administrations is for the most part for social motives, correspondence in the middle of loved ones part or for business motive (video-conferencing). Specialists can use this technology for patients' standard registration, to give the patient their analysis and an electronic remedy for minor cases like flu, cough, nourishment harming and so forth. This technology could likewise be utilized for subsequent treatment and in addition sparing time and transportation costs. E-health can oversee intense and unending conditions, Electronic infection administration projects are an essential part of the e-health upset, and are intended to modify the conveyance of consideration using technology to screen patients day by day to decide their health status, remind them to take their drugs, and handle issues before they turn out to be more genuine.' [1] While the world's populace expands, assets are getting scarcer. E-commerce is an astounding answer for medicinal services, since it utilizes rare assets as a part of the most productive way that can manage the soundness of a country. In [19] investigated the use of e-commerce to the industry of healthcare from the shoppers' and suppliers' perspectives. They talked about the dangers of e-trade and survey people in general and private reactions to handle these worries. E-health guarantees to enhance effectiveness, encourage correspondence in the middle of specialist and patient, screen consistence with therapeutic regimens, and absolutely effect on the nature of the given health administrations and the general soundness of the patient [14].

\subsection{The Advantages of E-health}

Numerous advantages of e-health are noted. They are that organizations and healthcare suppliers have an edge over contenders. Through CRM and SCM daily operations are coordinating exceptionally with focused technologies [14]. The medical field is very competitive integrating technology in the daily operations. The capacity to oversee patient's consistence, drug-regimens, and full health status and alarms human experts of required involvement, a shopper's entrance to clinical guidance, authority's referrals, conclusion test results, drug models and antagonistic responses. Effective utilization of assets empowers specialists, doctor's facility staff and medicinal services experts to treatment conventions and correspondence difficulties and status of patient. More noteworthy patient reaction and advancement with respect to treatment involvement, endorsed over thecounter meds and reactions to instructive endeavors by specialists. Specialists can bolster enhance patients' adherence to plans of treatment, convey better care, decrease expenses, and upgrade general consumer loyalty. Creating nations and rising economies can advantage since technology separates hindrances and allows them to get profitable therapeutic (medical) information and administrations like wealthier created countries. In [20] talks about the (WHO) World Health Organization and (OSI) the Open Society Institute, a part of the Soros Foundation, have collaborated with driving data suppliers, ISI and Silver Platter, and other open and private accomplices to give access to excellent experimental data by means of the Internet, for exploration focuses in creating nations like Africa, Central Asia, and Eastern Europe. 'This is a section of the United Nations program named as Health-Inter-Network which plans to upgrade worldwide [14] Research, and distributing the knowledge increased through its endeavours, is basic to enhancing open health.'[20] Ehealth and M-Health are illustrations of associating health of human with technology which is online. These method for correspondence are both useful yet one is more practical than the other. With the end goal this should work, it'll take the support and eagerness of numerous medicinal services suppliers and customers [14]. While E-health utilizes systems like the web and video conferencing, M-health is portable health which utilizes specialized devices like phones and remote systems [12]. M-health could be connected for general purposes just, there are confined ways and numerous obstructions/limitations contrasted with E-health. In [11] article, Eric Rock remarked that he trusts marks/watchwords like "M-health", "portable" have a constrained time frame of realistic usability and as existing apart from everything else, he trusts E-health has a much higher rate of progress. In the article [12] it talks about how e-commerce has affected the medicinal segment, which is still in an exceptionally fundamental manner.

\section{Case Study Description}

The business will join the offer of therapeutic (medical) gadgets through an online stage. The medicinal gadgets that will be sold join diverse gadgets having changing applications and unpredictability. The business will stock an assortment of gadgets including wheelchairs, expendable gloves, tongue depressors and therapeutic thermometers. Likewise, the business will offer complex therapeutic gadgets incorporating PCs to help with the examination of inside and outside states of the body. Because of the affectability of restorative (medical) gadgets there is a development of the regulation of medical gadgets in UAE. It is necessary to ensure that the medicinal gear that are sold meet the security prerequisites to guarantee that they are alright for using them in various restorative organizations all inclusive. Mention that the security of medicinal gadgets is relative 
since all medicinal gear conveys a level of danger; subsequently, there might be a rise of issues in given circumstances. In this manner, it is basic to guarantee that the gadget sold by means of the organization site meets the details that are put aside by both neighborhood and global norms.

\subsection{Objective}

The business goes for encouraging the little scale and huge scale supply of medicinal hardware in UAE. The customers will be required to buy the organizations utilizing the online stage that will be made. What's more, the customers will require imparting on their area and location that will join their delivery data. The principle finding of this model plans to expand the openness of the merchandise that are brought in from various makers. Thus, the business will speak with the customers to clear up any subtle elements that the customer may wish to examine in reference to the request put. It is essential to make a note on the utilization of online stages will undoubtedly build the scope of the business to various customers from all over U.A.E since anybody that wishes to get to the items that are offered by the business just require to get to the organization site [1].

\subsection{Local Market}

The market which is proposed for the medical devices that will be sold by the business is the United Arab Emirates neighborhood market. The business sector for the items is assessed as Table 1. Along these lines, the business must overhaul the supply systems to guarantee that there is an adequate stream of products into the business sector. What's more, the business will go for ensuring so as to expand their compass that differing natures of customers are considered in the improvement of the business objectives. Case in point, the business merchandise ought to be reasonable to the run of the mill shopper and expansive scale purchasers shape the online stage.

Table 1: Financial projection for the business.

\begin{tabular}{|l|l|l|l|}
\hline & Year 1 & Year 2 & Year 3 \\
\hline $\begin{array}{l}\text { Estimated } \\
\text { Sales }\end{array}$ & $\$ 500,000$ & $\$ 1,000,000$ & $\$ 1,500,000$ \\
\hline
\end{tabular}

\subsection{Model Processes}

Information organization is key to keeping up a productive business with respect to the $21 \mathrm{st}$ century. Every last business system can now be mapped and dismembered by data organization programming to propel business objectives and encourage the best possible administration of the business issues which are most complex. These data systems oblige information originators with a solid establishment in both business methods and Information Technology. Information systems (IS) and IT frameworks assume an indispensable part in advancing business forms including the administration of representatives and information on the business customers [24].

MIS/IT fortify the mix of various business procedures and exercises. As indicated by that, the organization arrangements to execute the requesting satisfies process keeping in mind the end goal to encourage and associate the execution and exercises of sales, bookkeeping and conveyance offices. Ordering satisfies process orchestrates business exercises in practical grouping. After create orders by sales division, sales submit it to bookkeeping that check and favor the instalments with a specific end goal to prepare and convey the items by conveyance office. As represented underneath in Fig. 1.

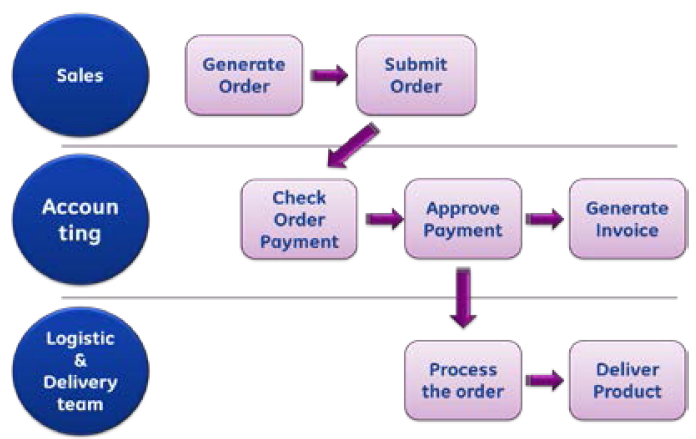

Figure 1: On-line order processing and fulfilment diagram

\subsection{Findings}

With an end goal to lead a business sector overview, 50 members were issued with a survey (see Table 2) which were went for analyzing the condition of the business sector and the buyer acknowledgment of the offer of therapeutic gear on the web. The consequences of this review will undoubtedly help in the change of the methodology towards the sale of medicinal gadgets online in the proposed business. The questionnaire results are summarized in Fig. 2.

\section{Table 2: Questionnaire}

1- Do you like to purchase your home use social insurance gear through the web or from Pharmacies/Healthcare Companies Showroom?

$$
\square \text { YES } \quad \square \mathrm{NO}
$$

2- What is the most advantageous installment payment path for you?

$$
\square \text { Cash } \quad \square \text { Credit }
$$

3- Do you incline toward restorative gear's incorporate programming which is associated with your PC to exchange results and slants and for SW overhaul?

$$
\square \text { YES } \quad \square \text { NO }
$$

4- What is the worthy conveyance period?
$\square 2$ Days
1 Week
$\square 1$ Month

5- Do you favor sites or portable applications? $\square$ Web $\quad \square$ Site $\quad \square$ Mobile Application 
From the review, 32 individuals favored purchasing form online stages. This pattern might be credited to the expanded assortment and simplicity of finding things in online stages. It is central to note that online stage give a perfect hunt streamlining in this manner furnishing the customer with a scope of things structure distinctive makers and diverse costs. Rather than logged off (offline) purchasing, customers can get to a scope of information that they can then utilize to look for options. Besides, there is an expansion in the availability of technological gadgets that are utilized to get to the web. Accordingly, the web has developed as a basic correspondence and exchanging stage for customers since it takes into consideration exchanging at the solace and comfort of the customer. The adaptability that is given by online sales will undoubtedly pull in customers in UAE.

28 individuals among those who responded wanted to pay for the endless supply of the products while 22 individuals wanted to pay before the conveyance of the merchandise. Online sales suffers from instabilities since the general population might question the quality of trusting and believing the online shop, especially toward the starting. In any case, the criticism that is gotten structure the customers has been ended up being a suitable strategy for gaging the validity of online shops. Subsequently, the business will go for supplying the merchandise to the customer in a solid way that will undoubtedly build the shopper trust in the item.

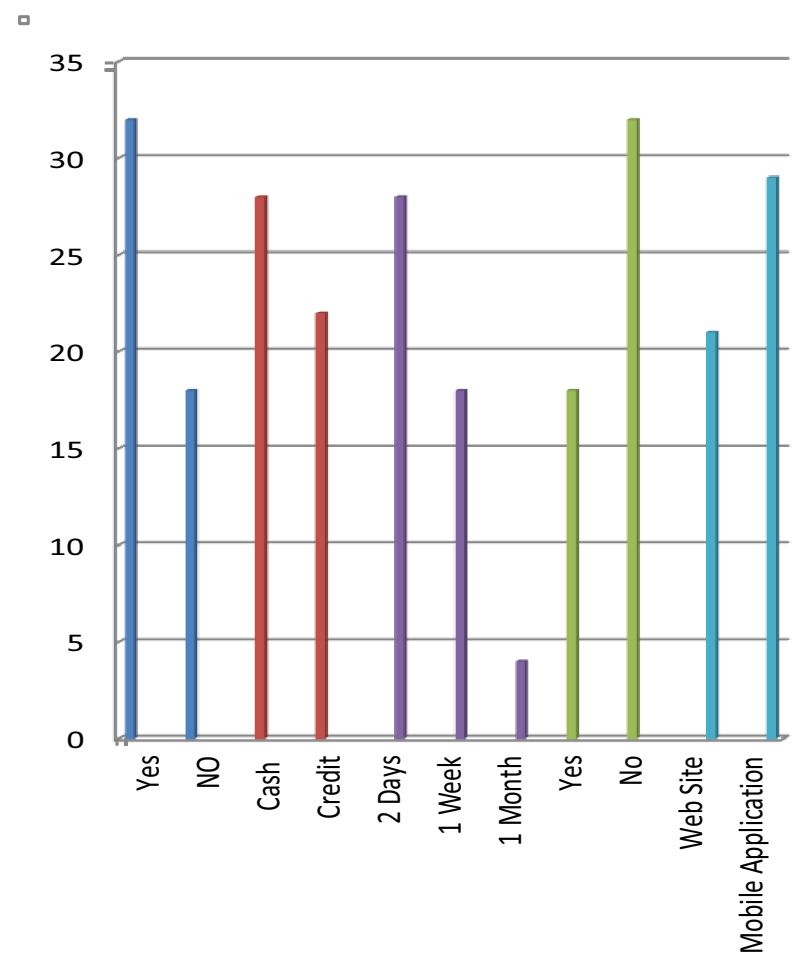

Figure 2: Questionnaire result diagram

Amid the review, the members were additionally requested that react to the time that they might want assign to conveyance of the item. The customers favored a shorter conveyance time to diminish the instability and improve the openness of the items after buy. It is clear that customers have a tendency to incline toward the enhancement of openness of the item. The trust of the buyers on the items sold online by the business will undoubtedly get expanded. Notwithstanding, it is indispensable to note that the lessening in the time taken for conveyance will undoubtedly expand the conveyance cost. Consequently, the business will see this as a venture to expand the shopper sales and trust in the organization [4].

The study additionally uncovered that 21 individuals favored utilizing sites while 29 individuals favored utilizing cell phone applications. This has uncovered the expansion in the gadgets that are accessible to get to the web therefore provoking the consolidation of cell phone applications. Hence, the business will add to a cell phone application that the clients can use in getting to the online store set up by the business. This will undoubtedly build the range of the business and expansion the prevalence and simplicity with which customers can buy products from the business on the web.

\section{Conclusion and Future work}

The strategies for success to venture into worldwide business sector. In any case, this requests more noteworthy interest with a specific end goal to encourage advertising and transportation of the items to various areas all inclusive. The UAE market shows an unexploited business sector that will undoubtedly encourage development of the business. Be that as it may, there is a need to expand the speculation on showcasing utilizing both online and logged off intends to build the quantity of customers. The economies of scale will be used by the business to guarantee that the items that are supplied by them is low in expense when compared to those created by the contenders.

Putting resources into MIS/IT expand association's productivity through minimizing the expense to maintain the business, give exact information to the leader and expansion consumer loyalty by coordinating their needs and convey a high values.

We have several ongoing activities, all concerned with extending our work to be more powerful and applicable. In what follows, we present some of these activities.

Linking this business with Telemedicine System will facilitate the consultation of doctors based on the kinds of the medical devices; online clinical interactive consultation and distance learning for special devices. A promising venue of research is to use Social Media for online buying decision. Social network such as Facebook, LinkedIn, Twitter, Google+, Pinterest, etc. have become an easy to login and purchase. Moreover, the customers can stay updated via the posts published on this media. 
Further, the advertising \& promotions on these social sites has increased the opportunities to success of generating transactions to many folds. One of the most important design goals of this research is to add Business Intelligence (BI) approach to this business. It will help the business to apply E-commerce, mobile apps and mobile payments and banking.

\section{References}

1. Amir, R. (n.d.), (2003) Market Structure, Scale Economies and Industry Performance. SSRN Journal.

2. Aggarwal AK1, Travers S., (2001) E-commerce in healthcare: changing the traditional landscape, J Healthc Inf Manag. Spring; 15 (1):25-36.

3. Australian National Electronic Health Records Taskforce, A Health Information Network for Australia, Report to Health Ministers by the National Electronic Health Records Taskforce (Commonwealth Department of Health and Aged Care, Canberra, 2000) p 21 (hereinafter Taskforce).

4. Carrere, C. (2014). Regional Agreements and Welfare in the South: When Scale Economies in Transport Matter. Journal of African Economies, 23(3), pp.321-345.

5. Da Xu, L. (2014). Advances in e-business engineering management. Information Technology and Management.

6. Elmer, G. (2015). Going Public on Social Media. Social Media + Society, 1(1).

7. Ellen Hope Kearns, Suzanne C. Holmes, and Gerene Schmidt,(2002) The role of e-commerce in health care, Clinical report, SB \& E, Inc. (Science Business \& Education), Spokane, WA, U.S.A. CLMA/ ASCP, New Orleans, LA, June 26-29, 2002.

8. Fenton, N. (1991). Shaping the Future. Business Design through Information Technology. J Inf Technol, 6(3-4), pp.237-237.

9. Ivanov, I. (2007). Pharmaceutical and Medical Biotechnology. Biotechnology \& Biotechnological Equipment, 21(1), pp.74-79.

10. Jan de Vries and Robbert Huijsman, (2011) Supply chain management in health services, Supply Chain Management: An International Journal Volume 16 • Number 3 • 159-165.

11. Jeff Kagan, (2011), Why Don't Doctors and Patients eConnect Yet ? E-Commerce Times.

12. Jeff Kagan, (2011) The Fuse Is Lit for the mHealth Industry Explosion, E-Commerce Time.

13. Kauffman, R., Liu, J. and Ma, D. (2015). Technology investment decision-making under uncertainty. Information Technology and Management, 16(2), pp.153-172.

14. Luzanna C. and Rashad Y., (2011) Ecommerce's Important Role in the Medical Sector, International Conference on Information Communication and Management, IPCSIT vol.16 IACSIT Press, Singapore.

15. Medical equipment \& supplies. (1991). Journal of Air Medical Transport, 10 (3), pp.62-63.
16. Mdnr.sfda.gov.sa, (2015). MDNR [Online] Available at:

https://mdnr.sfda.gov.sa/MDNR/Public/MedicalDevi ce.aspx [Accessed 20 May 2015].

17. Journal of Legal Medicine, Vol. 12, No. 1, 2004. Available at SSRN: http://ssrn.com/abstract=1265025.

18. Schneller, E.S., Schmeltzer, L.R. and Burns, L.R. (2006), Strategic Management of the Health Care Supply Chain, Jossey-Bass, San Francisco, CA.

19. Suzanne C. Holmes and Renee H. Miller, (2003), International Journal of Services Technology and Management, Volume 4, Numbers 4-6, pages507 517.

20. Suman Kapur, (2001) The Internet: Its Role in Medicine and Healthcare, Journal, Indian Academy of Clinical Medicine Vol. 2, No. 3 July-September, 10 , p. 133-138.

21. Tarasewich $P$, Nickerson $\mathrm{RC}$ and Warkentin $\mathrm{M}$ (2002) Issues in mobile. Commerce Communications of the Association for Information Systems 8(2002), 41-64.

22. Tan, F. (1995). The responsiveness of information technology to business strategy formulation: an empirical study. J Inf Technol, 10(3), pp.171-178.

23. Terry, Nicolas P., (March 8, 2004), Electronic Health Records: International, Structural and Legal Perspectives.

24. Vidgen, R. and Wang, X. (2006). From business process management to business process ecosystem. J Inf Technol, 21(4), pp.262-271.

25. Luigi T.De Luca, Propulsion physics (EDP Sciences, Les Ulis, 2009)

26. F. De Lillo, F. Cecconi, G. Lacorata, A. Vulpiani, EPL, 84 (2008) 